\title{
Spatiotemporal dynamics of impervious surface areas across China during the early 21 st century
}

\author{
KUANG WenHui ${ }^{1}$, LIU JiYuan ${ }^{1 *}$, ZHANG ZengXiang ${ }^{2}$, LU DengSheng ${ }^{3} \&$ XIANG Bao ${ }^{4}$ \\ ${ }^{1}$ Institute of Geographic Sciences and Natural Resources Research, Chinese Academy of Sciences, Beijing 100101, China; \\ ${ }^{2}$ Institute of Remote Sensing Application, Chinese Academy of Sciences, Beijing 100101, China; \\ ${ }^{3}$ Michigan State University, East Lansing, MI 48823, USA; \\ ${ }^{4}$ Chinese Research Academy of Environmental Sciences, Beijing 100012, China
}

Received August 26, 2012; accepted October 26, 2012;published online November 30, 2012

\begin{abstract}
China has experienced an unprecedented urbanization and industrialization in the past decades. In this research, we examined the dynamics of construction lands and impervious surface areas (ISA) based on land use/cover change and ISA datasets between 2000 and 2008, which were provided by the national resources and environmental remote sensing information platform. The results indicated that the construction areas and ISA increased by 3468.30 and $2212.24 \mathrm{~km}^{2} / \mathrm{a}$ in this period primarily due to the implementation of national macro-development strategies and fast-growing economy. In 2008, ISA accounted for $0.86 \%$ of the total land area in China. Urban land areas increased by $43.46 \%$ between 2000 and 2008 . The annual growth rate of $1788.22 \mathrm{~km}^{2} / \mathrm{a}$ in this period was 2.18 times that in the 1990s. In particular, urban ISA increased by $53.30 \%$ between 2000 and 2008 with an annual growth rate of $1348.85 \mathrm{~km}^{2} / \mathrm{a}$. During the 8 years, the ISA in China increased rapidly, especially in the Beijing-Tianjin-Tangshan Metropolitan Region, Pearl River Delta, Yangtze River Delta, and the western China region. The increasing ISA may influence potentially water environmental quality in the major basins. In particular, the number of subbasins having ISA of greater than $10 \%$ increased considerably, which were primarily distributed in the Haihe River, Yangtze River and Pearl River basins. In $2008,14.42 \%$ of the basin areas were affected by the increased ISA.
\end{abstract}

construction land, urban expansion, impervious surface area, remote sensing, China

Citation: Kuang W H, Liu J Y, Zhang Z X, et al. Spatiotemporal dynamics of impervious surface areas across China during the early 21 st century. Chin Sci Bull, 2013, 58: 1691-1701, doi: 10.1007/s11434-012-5568-2

Urbanization has become a hotspot in the 21st century [1-7]. Urbanization as one of the important conversions from natural lands to construction lands may exert profound influences on biogeochemical cycle, hydrological process, climate change, and biodiversity in the terrestrial ecosystems at local, regional and global scales [1-4]. Therefore, urban ecology and urban environmental sciences become vital research fields in the global environmental changes.

Population in the urban area is increasing continuously in recent decade. Over half of population in the world lived in urban areas in 2008 [8,9]. China's urban population increased with a rate of $1.2 \% / \mathrm{a}$ and accounted for $45.77 \%$ of

*Corresponding author (email: liujy @igsnrr.ac.cn) its total population in 2008 [10]. In particular, the national land development policies such as the Western Development Program, the regional development strategies such as International Metropolis Construction (Economic zones), and the key construction projects further resulted in the expansions of urban impervious surface areas (ISA). The rapid urbanization has raised concerns for "rash advance" or "uncontrolled urban space", which is deviated from the principle of gradual and orderly development and the quality and sustainability of urbanization $[11,12]$. This could further cause serious environmental problems in China $[13,14]$.

ISA is an important indicator for assessing the land conversion from natural ecosystems to human-dominant eco- 
systems at multiple spatial-temporal scales $[1-4,15,16]$. Use of ISA for quantitatively evaluating urbanization, for assessing global environmental change and urban ecology, and for analyzing climate change has obtained increasingly attention [6,15-26]. Since Ridd [19] proposed a V-I-S (Vegetation-Impervious Surface-Soil) model to explain urban landscape, much progress has been made in mapping urban land use/cover and ISA distribution. USGS (U.S. Geological Survey) employed Landsat Thematic Mapper (TM) images to develop the 2001 and 2006 ISA datasets at a national scale [20,21]. U.S. EPA (Environmental Protection Agency) predicted future growth patterns of ISA and its impact on spatial-temporal patterns of surface water environment across conterminuous U.S. [6]. U.S. NOAA (National Oceanic and Atmospheric Administration) developed global ISA datasets at $1 \mathrm{~km}$ spatial resolution using DMSP-OLS data, indicating that China had the largest ISA amount comparing to other countries. The increased ISA in U.S., Europe, Japan, China and India have considerable impacts on surface water environmental quality [16].

To accurately assess the impacts of rapid urbanization on ecosystem biogeochemical cycles, climate and environment, it is vital to know the location, extent, and controlling mechanisms of construction land expansion in China [27, 28]. Since the digital decoding of China's land use/cover change (LUCC) datasets cannot effectively partition intra-urban ISA, ecological land, and bare soil, quantitatively evaluating and analyzing urbanization process and its impacts on ecology, environment and climate are inadequate. This study aims to quantitatively examine the spatiotemporal patterns of construction land and its impacts on land surface water environment in order to provide new insights for policy-makers to develop regional urban development plans.

\section{Methods}

\subsection{Data collection and analysis}

The LUCC data between 2000 and 2008, which were provided by the national resources and environmental remote sensing information platform $[29,30]$ were used in this research. Meanwhile, MODIS NDVI, DMSP-OLS data, and administration boundary maps at basin, subbasin, and city scales were also used to acquire construction land and ISA data for analyzing their spatiotemporal characteristics. The 2000 LUCC dataset was mainly developed from Landsat TM images, and the 2008 LUCC dataset was developed from both Landsat TM and CBERS-2 CCD images by using computer-aided interactive methods $[29,30]$. The subbasin boundaries were extracted from the integration of USGS 1 km DEM data (http://eros.usgs.gov/\#/Find_Data/Products_ and_Data_Available/gtopo30/hydro/asia), the major and tributary river basin boundaries were from the Data Center for Resources and Environmental Sciences Chinese Acad- emy of Sciences, and the administration boundaries were from National Geometrics Center of China. Through integration of boundaries at subbasin and the major and tributary river basins, a basin boundary map with higher accuracy was finally developed.

The construction land in this study was defined as bulitup land, including urban land, rural settlements and industrial land outside cities [29-31]; urban land was defined as small, medium and large cities and towns, including commercial land, transportation roads, squares, parks, lawns, etc. [32]; impervious surface was defined as the man-made surface that water cannot infiltrated into, including building roofs, paved roads, parking lots, etc. [23-25]. The methods for generating ISA data were referred to Lu et al. [22], in which a Human Settlement Index (HSI) was used with the combination of MODIS NDVI and DMSP-OLS data [22]. In this research, the ISA formula can be expressed as

$$
\mathrm{ISA}_{\text {index }}=\mathrm{HSI} \cap \mathrm{ACIS}_{\text {mask }} \text {, }
$$

where ISA $_{\text {index }}$ is the impervious surface index, i.e. the proportion of ISA in a cell size of $250 \mathrm{~m}$ by $250 \mathrm{~m}(0-100 \%)$; $\mathrm{ACIS}_{\text {mask }}$ is the code for a construction or urban land mask. HSI is human settlement index extracted by the combination of MODIS NDVI and DMSP-OLS.

\subsection{Accuracy assessment}

High spatial resolution images were used to assess the classification accuracy for construction land and ISA. These images included aerial photos for Beijing in $2008(0.2 \mathrm{~m}$ spatial resolution), Quickbird images for Changchun (0.61 m spatial resolution), ALOS and SPOT5 images for coastal regions such as Tianjin and Shanghai metropolitans, Hebei, Shandong, Liaoning and Guangdong provinces in 20072008 (2.5 m spatial resolution), and Quickbird images from Google Earth for some regions of the central and western China in 2008 (reprocessed as $2.5 \mathrm{~m}$ cell size). After rectification, all of these images were transformed and projected to the same coordinate system [32]. Meanwhile, field investigations for all provinces except Taiwan were conducted in 2008 and 2009 for acquiring the local knowledge on land use change and validating the interpreted dataset. Approximately $10 \%$ of the China's counties were randomly selected and field investigation data were used to assess classified images. The accuracy assessment result indicated that the overall accuracy reached over $95 \%$, in particular, the accuracy for suburban residential land and transportation roads had accuracy of over $98 \%[29,30]$.

To assess ISA classification accuracy, 676 samples with each grid size of $750 \mathrm{~m} \times 750 \mathrm{~m}$ were randomly sampled within China. The ISA reference data were developed from high spatial resolution images as mentioned above by digitization. Meanwhile, field work for some megacities such as Beijing, Tianjin, Harbin, and Huhhot were conducted. Correlation coefficient $(R)$ and mean relative estimation error 
(MRE) were used to evaluate ISA mapping performance [25]. The equations for calculating $R$ and MRE were

$$
\begin{gathered}
R=\frac{\sum_{i=1}^{n}\left(x_{i}-\bar{x}\right)\left(y_{i}-\bar{y}\right)}{\sqrt{\sum_{i=1}^{n}\left(x_{i}-\bar{x}\right)^{2} \cdot \sum_{i=1}^{n}\left(y_{i}-\bar{y}\right)^{2}}}, \\
\operatorname{MRE}=\frac{\sum_{i=1}^{n}\left(\left|x_{i}-y_{i}\right| / y_{i}\right)}{n},
\end{gathered}
$$

where $R$ and MRE are correlation coefficient and mean relative estimation error; $x_{i}$ and $y_{i}$ are ISA percentages of estimates and reference data in each 3 by 3 grid cell; $\bar{x}$ and $\bar{y}$ are the mean values of $x_{i}$ and $y_{i}$.

The LUCC datasets which were developed by using human-computer interactive interpretation can reflect construction lands and city boundaries with high accuracy, but cannot reflect the internal structures that are closely related to the urban environment and climate locally or regionally. The HSI based method, which was developed by integrating MODIS NDVI and DMSP-OLS data, can rapidly extract the ISA dataset in a large area. The accuracy assessment result for ISA data indicated the high correlation coefficient of 0.92 and relatively low MRE of $0.64 \%$. Since the ISA estimation errors were mostly less than $20 \%$ (Figure 1), the results were met the requirement for use at a national scale.

\subsection{Spatial analysis}

Land use dynamic model was used to analyze the dynamic change of construction lands, urban lands, and ISA based on the 2000 and 2008 LUCC and ISA datasets [30]. This model is expressed as

$$
S=\left\{\sum_{i j}^{n}\left(\Delta S_{i-j} / S_{i}\right)\right\} \times(1 / t) \times 100 \%,
$$

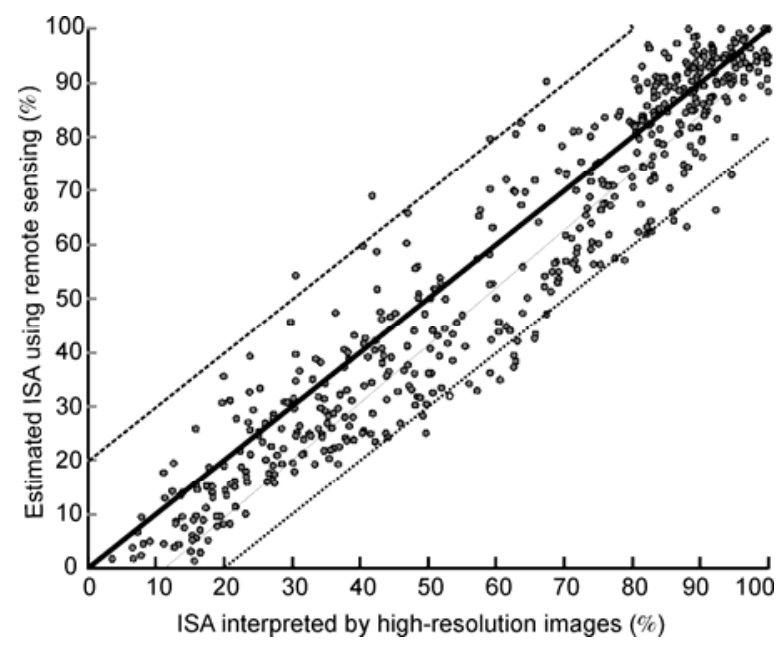

Figure 1 Relationship between ISA estimates and reference data. where $S_{i}$ represents the total areas of construction lands, urban lands, and ISA at the initial time; $\Delta S_{i-j}$ represents the total areas converted to construction lands, urban lands, and ISA between the initial time and the end time; $t$ represents time period; and $S$ represents the dynamic change of construction lands, urban lands, and ISA respectively in the study area.

Remote sensing-based ISA mapping and its impacts on ecology and environment have obtained increasing attention in the past several decades [15,16,33-36]. Previous research has indicated that the proportion of ISA in a unit has significant relationship with the potential health situation on watershed ecosystems [6], and this relationship was defined as five categories - unstressed, lightly stressed, stressed, impacted, and damaged, according to the thresholds of ISA proportions in a unit. In this research, the ISA index model is defined as

$$
\operatorname{WIS}(\beta)_{\text {index }}=\left(\sum_{x y}^{m} P_{x y} \times A_{x y} \times N_{x y}\right) / S_{\beta} \times 100 \%,
$$

where WIS $(\beta)_{\text {index }}$ represents ISA index in a watershed $\beta$; $P_{x y}, A_{x y}$, and $N_{x y}$ represent the ISA proportion, pixel area and number in a unit $(x, y)$; and $S_{\beta}$ is the watershed total area.

The WIS $(\beta)_{\text {index }}$ was used to evaluate the impacts of ISA on surface water environment in a watershed $[6,15,16]$, and is expressed as

$$
\mathrm{WIS}(\beta)_{\text {index }} \in\left\{\begin{array}{lc}
0-1 \% & \text { unstressed; } \\
1 \%-5 \% & \text { lightly stressed; } \\
5 \%-10 \% & \text { stressed; } \\
10 \%-25 \% & \text { impacted; } \\
25 \%-100 \% & \text { damaged }
\end{array}\right.
$$

\section{Resultant analysis}

\subsection{Spatiotemporal patterns of construction land expansion}

The analysis of spatial characteristics of construction lands based on the 2000 and 2008 LUCC data indicates that the construction area in China increased by $27746.39 \mathrm{~km}^{2}$ between 2000 and 2008 (Table 1). In particular, urban land area increased by $14305.74 \mathrm{~km}^{2}$, almost half of the total increased construction areas during the same period. The rapid urbanization and industrialization in this period expedited the land cover transform from natural to construction lands.

The rates of construction land expansion varied considerably in China, as shown in Figure 2. Overall, BeijingTianjin-Tangshan Metropolitan Region, Yangtze River Delta, and Pearl River Delta had highest expansion rates, following by the western China. Central and northern China had the lowest rates. Specifically, Shandong and Guangdong provinces had the highest expansion areas of about 
Table 1 The dynamics of construction areas between 2000 and $2008\left(10000 \mathrm{~km}^{2}\right)$

\begin{tabular}{|c|c|c|c|c|}
\hline \multirow{2}{*}{ Administrative regions } & \multicolumn{2}{|c|}{ Construction area change } & \multicolumn{2}{|c|}{ Urban area change } \\
\hline & Area change & Change rate $(\%)$ & Area change & Change rate $(\%)$ \\
\hline Beijing & 567.19 & 3.15 & 387.36 & 4.68 \\
\hline Tianjin & 498.80 & 3.42 & 315.53 & 7.11 \\
\hline Hebei & 1354.35 & 1.25 & 637.40 & 4.14 \\
\hline Shanxi & 615.43 & 1.81 & 242.10 & 3.07 \\
\hline Inner Mongolia $^{\text {a) }}$ & 650.09 & 0.72 & 193.71 & 2.09 \\
\hline Liaoning & 514.28 & 0.73 & 240.69 & 1.92 \\
\hline Jilin & 243.90 & 0.46 & 205.70 & 2.52 \\
\hline Heilongjiang & 267.87 & 0.38 & 101.02 & 0.92 \\
\hline Shanghai & 784.97 & 6.83 & 221.40 & 3.56 \\
\hline Jiangsu & 2741.34 & 2.35 & 1268.79 & 5.60 \\
\hline Zhejiang & 2718.57 & 9.84 & 1311.26 & 14.31 \\
\hline Anhui & 1058.61 & 1.14 & 583.09 & 7.17 \\
\hline Fujian & 1941.86 & 10.59 & 633.77 & 12.39 \\
\hline Jiangxi & 651.66 & 2.85 & 339.88 & 7.27 \\
\hline Shandong & 3147.46 & 2.01 & 1852.73 & 7.46 \\
\hline Henan & 1006.67 & 0.72 & 843.27 & 4.87 \\
\hline Hubei & 655.39 & 1.59 & 303.06 & 3.27 \\
\hline Hunan & 626.79 & 2.70 & 271.44 & 3.55 \\
\hline Guangdong & 3283.07 & 5.01 & 2428.37 & 12.49 \\
\hline Guangxi ${ }^{\text {b) }}$ & 266.07 & 0.75 & 186.76 & 2.85 \\
\hline Hainan & 101.70 & 1.69 & 68.36 & 5.48 \\
\hline Chongqing & 495.74 & 10.16 & 307.22 & 11.70 \\
\hline Sichuan & 784.47 & 3.28 & 415.67 & 5.74 \\
\hline Guizhou & 83.82 & 1.74 & 40.46 & 2.01 \\
\hline Yunnan & 316.87 & 1.94 & 175.63 & 4.20 \\
\hline Tibet $^{c)}$ & 32.63 & 3.16 & 22.92 & 5.42 \\
\hline Shaanxi & 468.61 & 1.86 & 164.61 & 3.73 \\
\hline Gansu & 291.55 & 1.02 & 94.22 & 2.90 \\
\hline Qinghai & 383.89 & 4.76 & 22.48 & 2.17 \\
\hline Ningxia $^{\text {d) }}$ & 322.71 & 3.96 & 127.74 & 11.68 \\
\hline Xinjiang ${ }^{\mathrm{e})}$ & 641.00 & 1.83 & 181.06 & 2.20 \\
\hline Taiwan & 222.26 & 1.64 & 112.31 & 1.29 \\
\hline Hong Kong & 6.77 & 0.55 & 5.73 & 0.60 \\
\hline Total & 27746.39 & 2.00 & 14305.74 & 5.43 \\
\hline
\end{tabular}

a) Inner Mongolia: Inner Mongolia Autonomous Region; b) Guangxi: Guangxi Zhuang Autonomous Region; c) Tibet: Tibet Autonomous Region; d) Ningxia: Ningxia Hui Autonomous Region; e) Xinjian: Xinjiang Uygur Autonomous Region (the same below).

$3000 \mathrm{~km}^{2}$, followed by Jiangsu and Zhejiang provinces with over $2000 \mathrm{~km}^{2}$, and Hebei, Anhui, Fujian, and Henan provinces with over $1000 \mathrm{~km}^{2}$. Considering the rates of construction land expansion, Fujian Province and Chongqing City had the highest $(>10 \%)$ expansion rates, followed by Zhejiang Province and Shanghai City in the Yangtze River Delta, and Guangdong Province in the Pearl River Delta (over 5\%), and Beijing and Tianjin cities in the BeijingTianjin-Tangshan Metropolitan Region (over 3\%). The implementation of Western Development Policy resulted in relatively high urbanization rates in western China, thus, Qinghai Province and Ningxia had urban expansion rates of over $4 \%$, followed by Sichuan Province and Tibet by over
3\% (Table 1). In contrast, northeastern and northern China (e.g. Jilin, Liaoning, Heilongjiang provinces and Inner Mongolia) had the lowest expansion rates by less than $1 \%$.

Urban expansion accounted for the largest proportion of the increased construction lands. Between 2000 and 2008, Guangdong Province had the highest urban expansion areas of over $2000 \mathrm{~km}^{2}$, followed by Shandong, Zhejiang, and Jiangsu provinces of over $1000 \mathrm{~km}^{2}$; but Hainan, Guizhou, Tibet, Gansu, Qinghai, and Hong Kong had the lowest expansion areas of less than $100 \mathrm{~km}^{2}$. Considering the increasing rates during the 8 years, Zhejiang, Fujian, Guangdong, Chongqing, and Ningxia had the highest $(>10 \%)$ expansion rates. The high expansion rates in Zhejiang, Fujian 


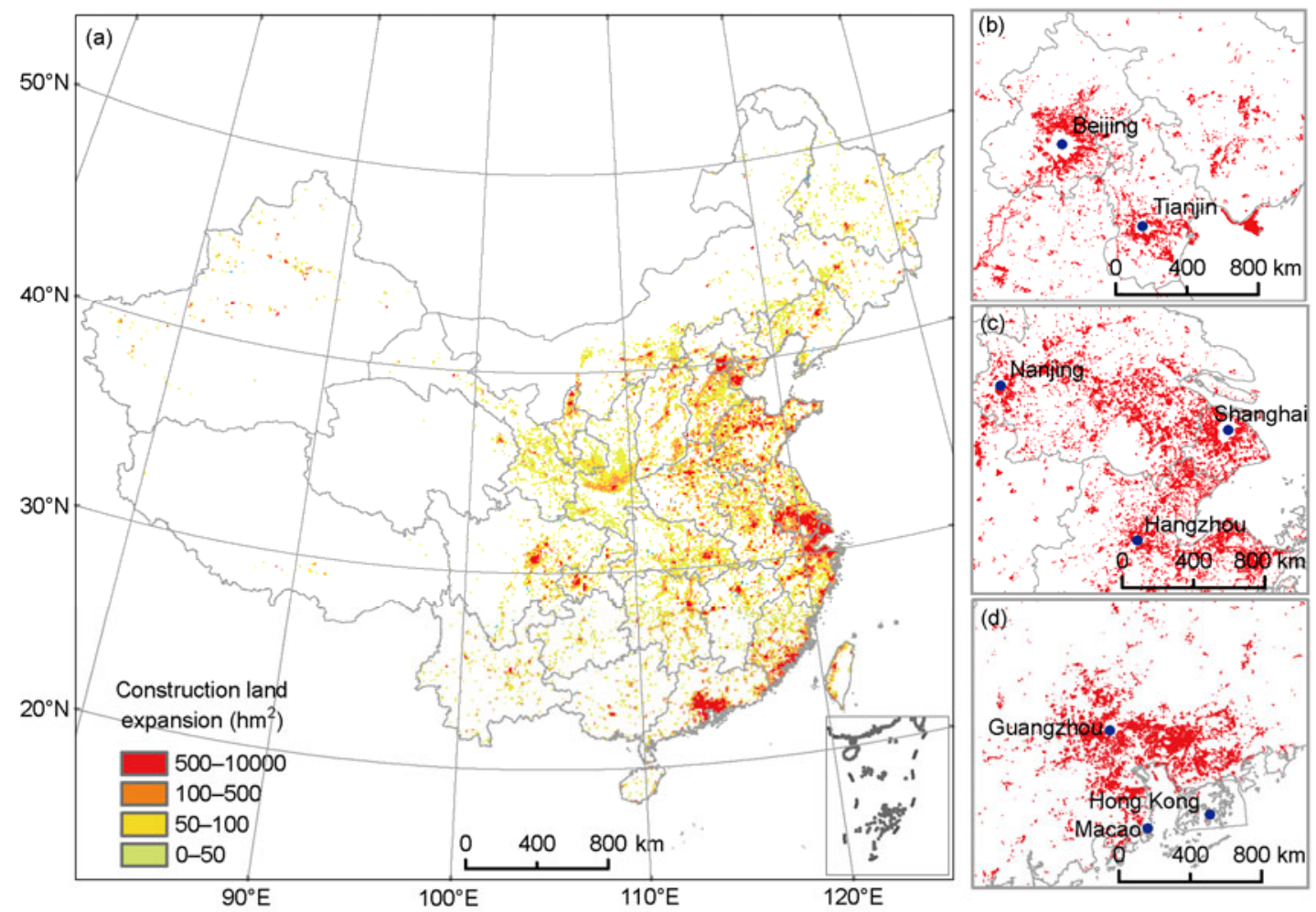

Figure 2 (a) Spatial distribution of construction land dynamics between 2000 and 2008. Left: cell size of a $10 \mathrm{~km} \times 10 \mathrm{~km}$; right: construction expansion areas in three metropolitans in vector format: Beijing-Tianjin-Hebei (b); Yangtze River Delta (c); Pearl River Delta (d).

and Guangdong in coastal regions were primarily due to export-oriented economy, and the other two regions were due to the increased investments in fixed assets benefitted from the Western Development Policy. Overall, the urban expansion rates decreased in the following order: the coastal regions in southern and southeastern China > western China $>$ northern China $>$ central China $>$ northeastern China. The constraint of resources availability in Beijing and Shanghai resulted in slow-down of their urban expansion rates.

\subsection{Dynamic analysis of impervious surface areas}

The ISA distributions in 2000 and 2008 as shown in Figure 3 indicate that overall ISA spatial characteristics are similar to the trends of construction land change. The ISA expansion rates varied considerably in different provinces in China due to their differences in topography, climate and urban planning. The ISA increased by $17697.88 \mathrm{~km}^{2}$ with an annual increasing rate of $2212.24 \mathrm{~km}^{2} / \mathrm{a}$ between 2000 and 2008 (Table 2). Urban ISA accounted for $60.97 \%$ of the total ISA. During this period, the ratio of construction ISA to construction land was changed from $36.42 \%$ to $41.08 \%$. The ISA density in built-up areas was much higher than in rural residential areas, transportation and mining lands. Specifically, Zhejiang and Fujian had the highest ISA expansion rates (over 10\%): Pearl River Delta, Yangtze River
Delta and Beijing-Tianjin-Tangshan metropolitans were three major regions having high expansion rates (Figure 4). Analysis of inner urban structures indicated that the greater the urban extent, the higher ratio of ISA density. Lowlatitude cities (e.g. cities in east China) had relatively lower ISA density than high-latitude cities (western parts). Figure 4 also indicates that ISA expansion was mainly along the city frontiers, that is, the medium and small cities surrounding megacities had rapid ISA expansion rates because the constraints of resources and environments in megacities resulted in the transfer of development foci from megacities to surrounding cities. The ISA expansion rates in western China were considerably accelerated due to the influence of "Western Development Policies". The rapid increase of ISA density in coastal regions and western China exacerbated the ecological and environmental vulnerability to a certain degree.

\subsection{Impacts of impervious surface expansion on surface water environments}

The analysis of ISA distribution in 2000 and 2008 and the boundaries of subbasins as shown in Figure 5 and Table 3 indicated that ISA in the category of greater than $1 \%$ accounted for $12.43 \%$ of the total area in 2000 and the ISA proportion increased to $14.42 \%$ in 2008 . The total area for ISA category of greater than $25 \%$ increased from $2845 \mathrm{~km}^{2}$ in 

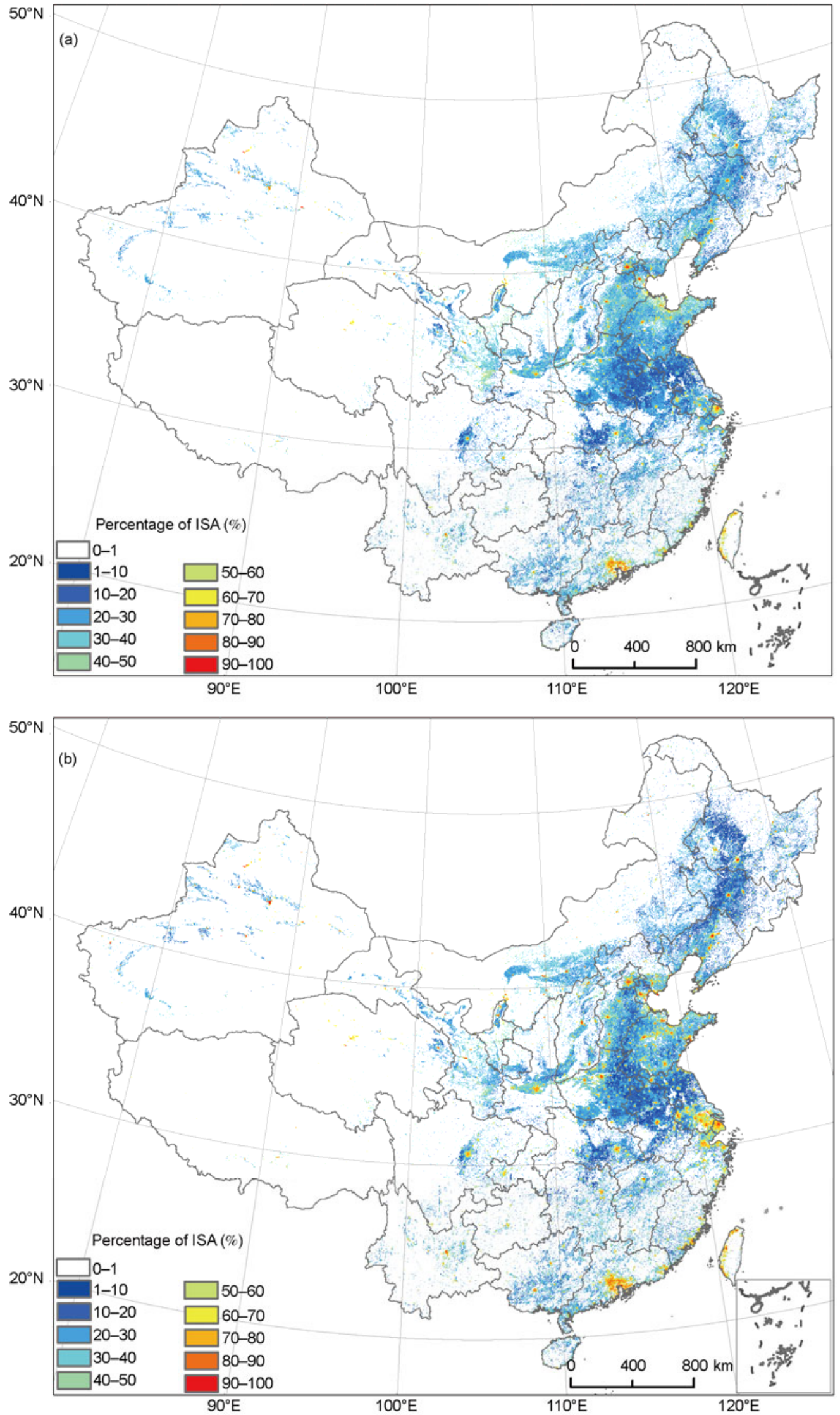

Figure 3 Distribution of impervious surface areas across China in 2000 (a) and in 2008 (b). 
Table 2 Statistical results of impervious surface areas and their dynamic changes between 2000 and $2008\left(10000 \mathrm{~km}^{2}\right)$

\begin{tabular}{|c|c|c|c|c|c|}
\hline \multirow[b]{2}{*}{ Administrative regions } & \multicolumn{2}{|c|}{ Constructed impervious surface change } & \multicolumn{3}{|c|}{ Urban impervious surface change } \\
\hline & $\begin{array}{c}\text { Increased areas in } \\
2000-2008\end{array}$ & $\begin{array}{c}\text { Dynamic change } \\
(\%)\end{array}$ & $\begin{array}{c}\text { Increased areas in } \\
2000-2008\end{array}$ & $\begin{array}{l}\text { Impervious surface } \\
\text { ratio in } 2008(\%)\end{array}$ & $\begin{array}{c}\text { Dynamic change } \\
(\%)\end{array}$ \\
\hline Beijing & 332.84 & 3.33 & 213.25 & 72.60 & 3.25 \\
\hline Tianjin & 315.91 & 4.18 & 189.27 & 74.01 & 5.34 \\
\hline Hebei & 767.03 & 1.79 & 481.62 & 67.09 & 4.87 \\
\hline Shanxi & 457.56 & 3.43 & 260.22 & 74.45 & 4.97 \\
\hline Inner Mongolia & 470.61 & 1.56 & 262.58 & 71.37 & 4.66 \\
\hline Liaoning & 396.82 & 1.41 & 241.28 & 72.40 & 2.83 \\
\hline Jilin & 194.29 & 1.17 & 171.03 & 67.80 & 3.24 \\
\hline Heilongjiang & 220.34 & 0.91 & 159.35 & 71.00 & 2.26 \\
\hline Shanghai & 525.00 & 7.23 & 207.62 & 79.52 & 4.43 \\
\hline Jiangsu & 1980.10 & 5.41 & 1210.41 & 65.73 & 10.19 \\
\hline Zhejiang & 1536.23 & 13.67 & 851.80 & 61.05 & 16.63 \\
\hline Anhui & 668.28 & 3.04 & 484.18 & 62.23 & 11.85 \\
\hline Fujian & 982.00 & 11.21 & 371.86 & 60.96 & 11.84 \\
\hline Jiangxi & 414.73 & 5.88 & 269.73 & 58.49 & 12.44 \\
\hline Shandong & 1830.10 & 3.01 & 1187.67 & 63.58 & 7.62 \\
\hline Henan & 921.38 & 2.24 & 755.92 & 65.86 & 7.72 \\
\hline Hubei & 363.56 & 3.00 & 242.52 & 57.09 & 5.12 \\
\hline Hunan & 398.04 & 5.51 & 264.54 & 56.40 & 7.73 \\
\hline Guangdong & 1940.98 & 5.44 & 1210.03 & 62.18 & 8.50 \\
\hline Guangxi & 248.86 & 2.16 & 194.51 & 63.53 & 5.47 \\
\hline Hainan & 70.48 & 2.96 & 47.34 & 64.70 & 6.15 \\
\hline Chongqing & 204.31 & 9.77 & 138.79 & 49.25 & 9.96 \\
\hline Sichuan & 505.89 & 6.55 & 358.91 & 61.19 & 9.99 \\
\hline Guizhou & 72.27 & 3.70 & 47.34 & 59.66 & 4.66 \\
\hline Yunnan & 205.21 & 3.12 & 136.68 & 66.99 & 5.16 \\
\hline Tibet & 32.61 & 6.29 & 25.59 & 79.99 & 9.13 \\
\hline Shaanxi & 235.55 & 2.54 & 151.55 & 66.96 & 5.78 \\
\hline Gansu & 177.54 & 1.64 & 107.38 & 78.53 & 4.70 \\
\hline Qinghai & 263.25 & 7.51 & 24.56 & 71.91 & 3.61 \\
\hline Ningxia & 217.57 & 6.69 & 118.57 & 82.40 & 14.93 \\
\hline Xinjiang & 533.90 & 3.75 & 247.69 & 78.52 & 4.40 \\
\hline Taiwan & 214.65 & 2.37 & 156.99 & 77.22 & 2.56 \\
\hline Hong Kong & 2.88 & 0.32 & 2.88 & 74.20 & 0.40 \\
\hline Total & 17697.88 & 3.50 & 10790.80 & 65.91 & 6.66 \\
\hline
\end{tabular}

2000 to $7410 \mathrm{~km}^{2}$ in 2008 , and they were mainly distributed in the subbasins of Haihe, Yangtze and Pearl Rivers. Figure 5 also illustrated that the increased ISA during the 8 years with the damaged category (greater than 25\%) mainly located in those coastal regions having high population density and relatively good cultivation conditions, implying the potential influences of the ISA expansion on urban sustainability and ecosystem vulnerability.

Except the rivers in southwestern and southeastern that were not obviously influenced by the increased ISA, other rivers in China were influenced to a certain degree by the increased ISA, and they were mainly distributed in Huihe, Haihe, Yellow, Yangtze, and Pearl rivers, as shown in Fig- ure 6 . The ISA categories were changed by two higher levels in 65 subbasins, and were increased by one level in 79 subbasins. This research indicated that the rapid urbanization and industrialization since 2000 influenced the environments in the 7 major basins in China, especially in Haihe, Huihe, Yangtze, Yellow, and Pearl rivers.

\section{Discussion}

Urban lands were expanded by $82 \times 10^{4} \mathrm{hm}^{2}$ between 1990 and $2000[37,38]$ and by $143 \times 10^{4} \mathrm{hm}^{2}$ between 2000 and 2008. The annual urban expansion rates by using remote 

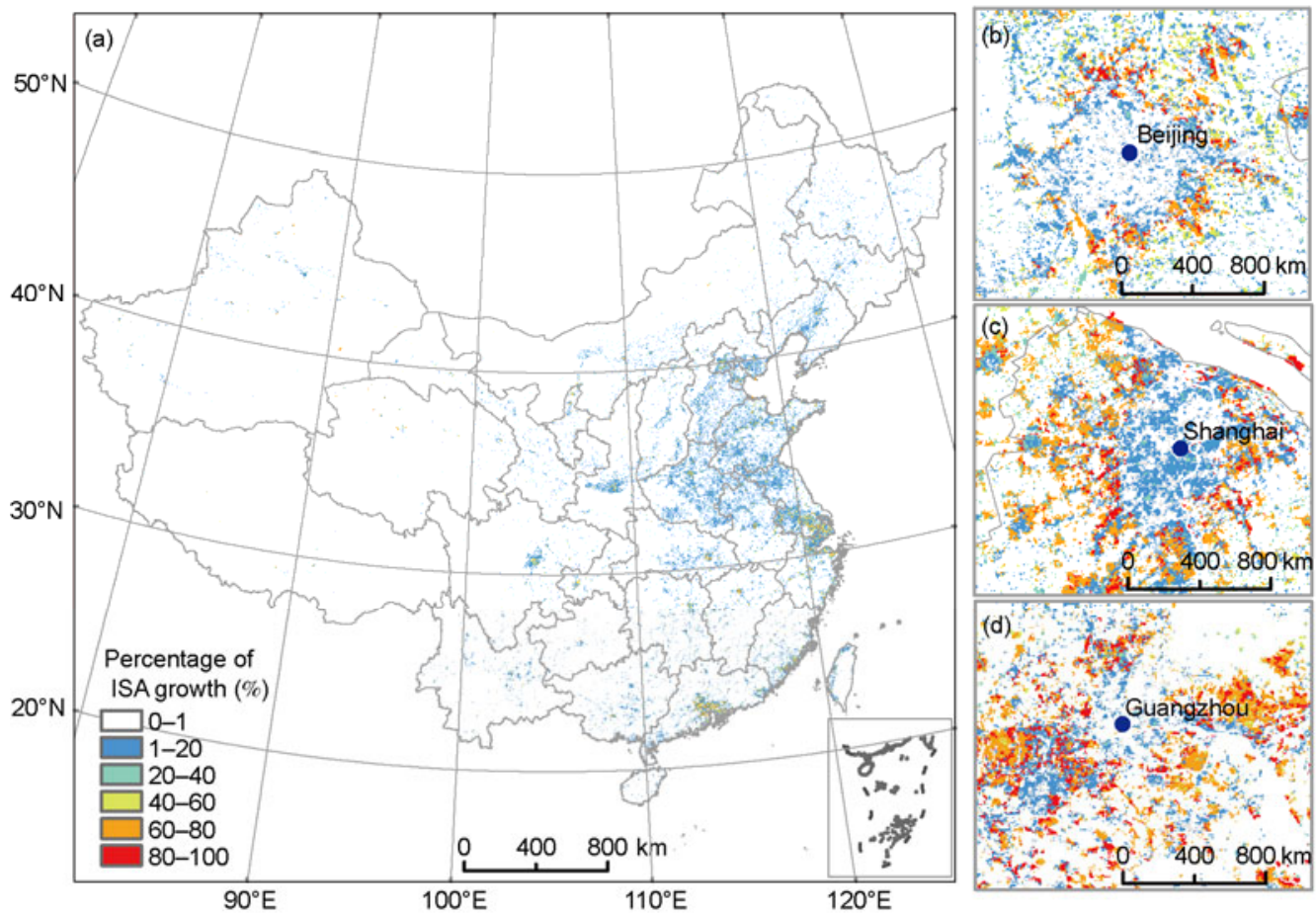

Figure 4 (a) Impervious surface expansion between 2000 and 2008. Left: $1 \mathrm{~km} \times 1 \mathrm{~km}$ grid cell; right: $250 \mathrm{~m} \times 250 \mathrm{~m}$ grid cell in Beijing (b), Shanghai (c); Guangzhou (d).

Table 3 Statistical results of impervious surface areas at different categories in major basins in 2000 and $2008\left(\mathrm{~km}^{2}\right)$

\begin{tabular}{|c|c|c|c|c|c|c|c|c|}
\hline \multirow{2}{*}{ Watershed } & \multicolumn{4}{|c|}{2000} & \multicolumn{4}{|c|}{2008} \\
\hline & Slightly stressed & Stressed & Impacted & Damaged & Slightly stressed & Stressed & Impacted & Damaged \\
\hline Yangtze River & 127662 & 8057 & 10397 & 2 & 149689 & 38128 & 17365 & 2292 \\
\hline Yellow River & 167785 & 14458 & 0 & 325 & 204601 & 18734 & 582 & 325 \\
\hline Pearl River & 104708 & 9252 & 8031 & 191 & 112651 & 3552 & 12274 & 3559 \\
\hline Songhua River & 53479 & 1276 & 676 & 19 & 65315 & 1730 & 676 & 19 \\
\hline Liaohe River & 72403 & 21119 & 114 & 12 & 69934 & 27112 & 115 & 12 \\
\hline Huaihe River & 256082 & 46340 & 3357 & 15 & 221356 & 82562 & 9283 & 23 \\
\hline Haihe River & 159096 & 30067 & 8643 & 2168 & 152987 & 48165 & 10057 & 3901 \\
\hline Rivers in Northwest & 15236 & 0 & 0 & 0 & 15592 & 0 & 0 & 0 \\
\hline Rivers in Southwest & 1642 & 0 & 0 & 0 & 1642 & 0 & 0 & 0 \\
\hline Rivers in Southeast & 43084 & 13846 & 20 & 113 & 57832 & 30484 & 5277 & 125 \\
\hline Total & 1001177 & 144415 & 31238 & 2845 & 1051599 & 250467 & 55629 & 10256 \\
\hline
\end{tabular}

sensing techniques in this research were consistent with the results from Wang and others [28]. Because of the urban expansion, ISA increased by $1348.85 \mathrm{~km}^{2} / \mathrm{a}$, and ISA accounted for $0.86 \%$ of the total area in 2008. The unprecedented urbanization rates across China in the first decade of the 21 st century have generated great challenges for Chinese government to make decisions for urban sustainability $[11,12]$.

According to the evaluation criteria used by US EPA [6], we examined the potential effects of China's ISA spatial distribution on surface water environments at basin levels, and found that the proportion of ISA-induced stressed areas
(ISA greater than 1\%) increased from $12.43 \%$ in 2000 to $14.42 \%$ in 2008 . The worse is that the areas in ISA damaged category (greater than 25\%) increased by 2.6 times in the 8 years between 2000 and 2008. The Haihe, Yangtze, and Pearl rivers were the major influenced regions. The rapid urbanization and industrialization exacerbated ecosystem vulnerability in the dense regions having population and key food production $[39,40]$.

Low Elevation Coastal Zones as a sensitive region by global climate change have obtained increasingly attentions [7]. With the rapid urbanization along the coastal regions, more population are moving to coastal zones from other 

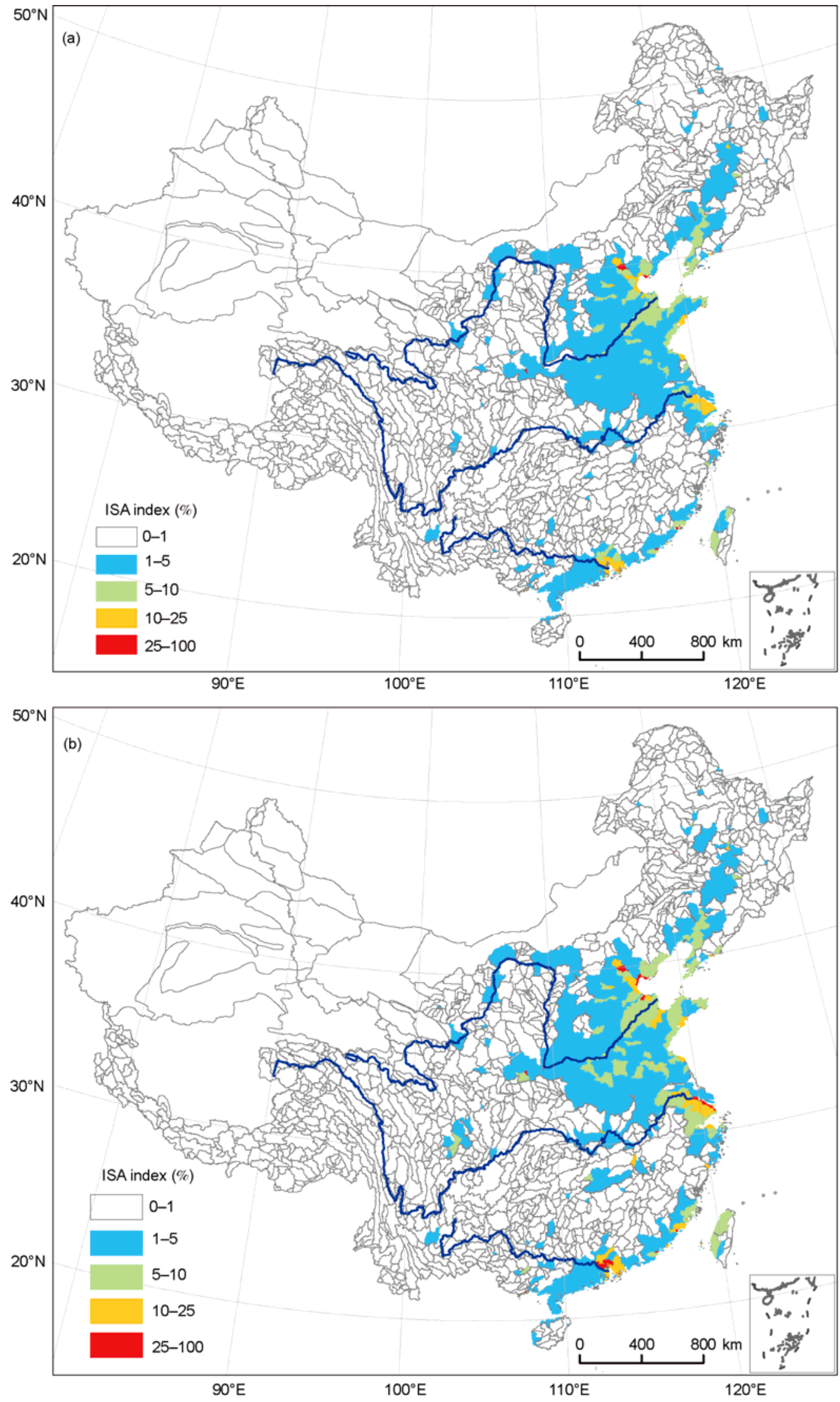

Figure 5 Impervious surface distribution at different ISA categories in 2000 (a) and 2008 (b). 


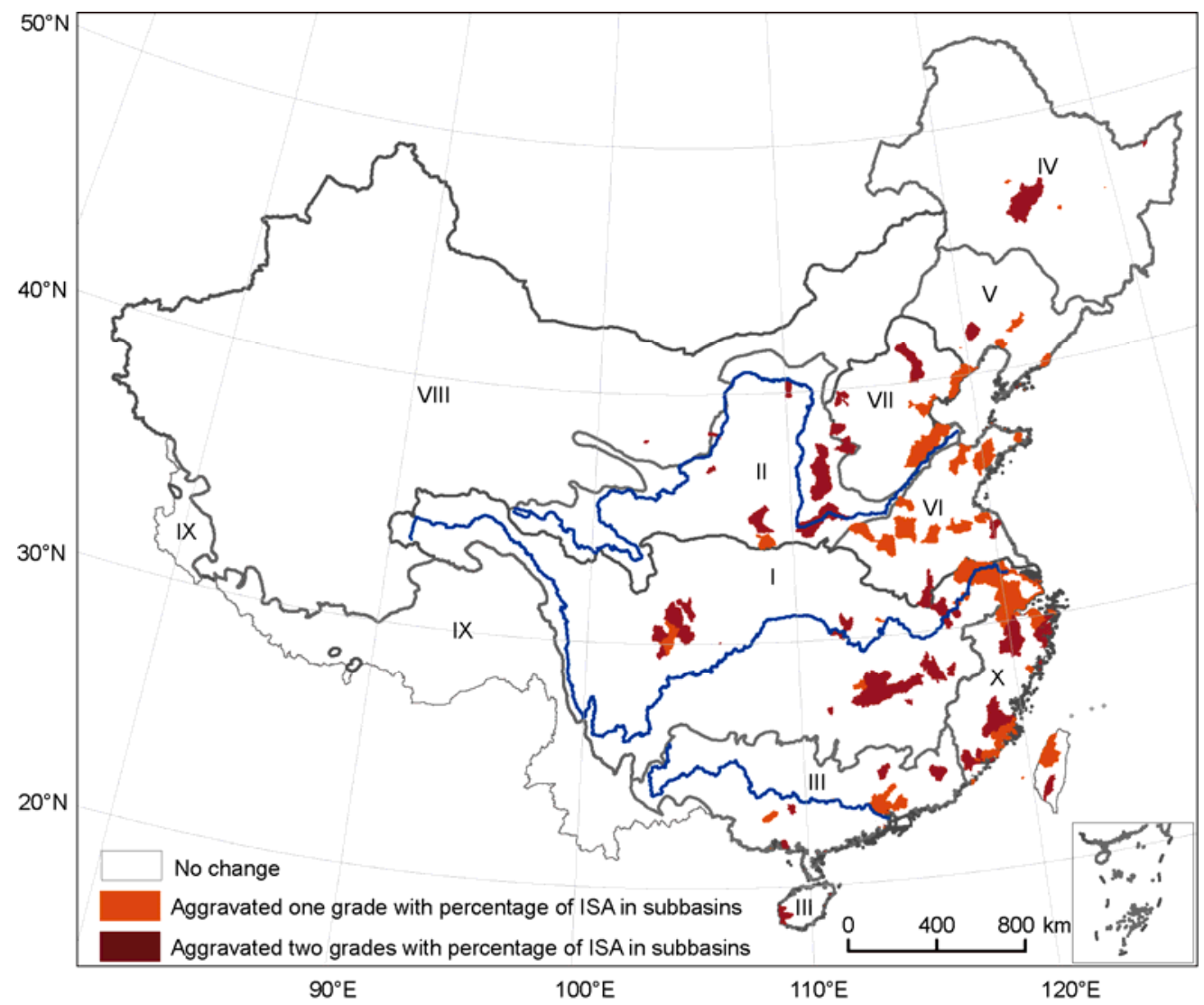

Figure 6 Impacts of impervious surface expansion on rivers between 2000 and 2008 in China. I, Yangtze River; II, Yellow River; III, Pearl River; IV, Songhua River; V, Liaohe River; VI, Huaihe River; VII, Haihe river; VIII, rivers in Northwest; IX, rivers in Southwest; X, rivers in Southeast.

regions, implying the increasing threats from the extreme weathers, such as floods, hurricanes and tsunamis. It is critical to take measures to enhance the adaptation in these regions in order to reduce the risks of natural disasters on urban sustainability.

This research based on examination of ISA spatial distribution and its impacts on surface water environments is valuable for further exploring the mechanisms of ISA expansion and environmental relationships. The ISA dynamic change information is also useful for other studies such as urban sprawl simulation models, ecological process models and climate change prediction models for examining the impacts of ISA increase on urban pollution, carbon and water cycling, and climate change. It is important to establish a comprehensive system of regional environmental simulation and prediction based on the relationship and interactions of urbanization - ecosystem - climate change - environmental effects $[31,32,41-43]$.

\section{Conclusions}

The new policies on land development and economic growth in the 21 st century have resulted in rapid urbaniza- tion with obviously different expansion patterns and rates in China. Between 2000 and 2008, construction lands increased by $16 \%$ and urban expansion by $43.46 \%$ with an annual expansion area of $1788.22 \mathrm{~km}^{2} / \mathrm{a}$. Beijing-TianjinTangshan metropolitans, Pearl River Delta, Yangtze River Delta and western regions having the highest construction expansion areas. Urbanization not only happened in urban-rural frontiers, but also changed in inner structure by increasing construction density. Because of the constraints of resources in megacities such as Beijing and Shanghai, urbanization in the megacities slowed down, but expanded rapidly in the surrounding medium and small cities. Because of rapid urbanization in China, the increasing ISA has important impacts on surface water environments in the major subbasins, especially in the subbasins of Haihe, Yangtze, and Pearl rivers.

This work was supported by the Young Scientist Fund of National Natural Science Foundation of China (40901224), the National Basic Research Program of China (2010CB950900), the National Water Special Project (2009ZX-07207-011), the National Key Technology R\&D Program (2012BAJ15B02), and the National High-Tech R\&D Program of China (2009AA122002). The authors would like to thank Prof. Zhang Shuwen, Wu Shixin, Zhou Wancun, Xu Xinliang, Li Rendong, Yan Changzhen, Pan Xianzhang, Jiang Nan and their teams for their assistance in LUCC data collection. 
1 Grimm N B, Faeth S H, Golubiewski N E, et al. Global change and the ecology of cities. Science, 2008, 319: 756-760

2 Alberti M. Advances in Urban Ecology Integrating Humans and Ecological Processes in Urban Ecosystems. New York: Springer Science + Business Media, 2009. 61-65

3 Pickett S A, Cadenasso M L, Grove J M, et al. Urban ecological systems: Scientific foundations and a decade of progress. J Environ Manage, 2011, 92: 331-362

4 Sánchez-Rodríguez R, Seto K C, Simon D. IHDP Report No. 15. Science Plan Urbanization and Global Environment Change. 2005

5 Parrish D D, Zhu T. Clean air for megacities. Science, 2009, 326: 674-675

6 Bierwagen B G, Theobald D T, Pyke C R, et al. National housing and impervious surface scenarios for integrated climate impact assessments. Proc Natl Acad Sci USA, 2010, 10: 1073-1078

7 McGranahan G, Balk D, Anderson B. The rising tide: Assessing the risks of climate change and human settlements in low elevation coastal zones. Environ Urban, 2007, 19: 17-37

8 Montgomery M R. The urban transformation of the developing world Science, 2008, 319: 761-764

9 United Nations. World Urbanization Prospects: The 2009 Revision. New York: United Nations, 2008

10 Nation Bureau of Statistics, PRC. China Statistical Yearbook 2009 (in Chinese). Beijing: China Statistics Press, 2009. 89-90

11 Lu D D, Ye D N. Restrain the rash advance of urbanization and the wild spatial expansion by integrated measures (in Chinese). Science News (Forum of Academician), 2007, 8: 5-9

12 Lu D D. Haven't get rid of the rash advance error of urbanization (in Chinese). People's Tribune (Specials), 2010, 7: 26

13 Richard S. Beijing's marathon run to clean foul air nears finish line. Science, 2008, 321: 636-637

14 Normile D. China's living laboratory in urbanization. Science, 2008, 319: 740-743

15 Arnold C L, Gibbons C J. Impervious surface coverage: The emergence of a key environmental indicator. J Am Plann Assoc, 1996, 2: 243-258

16 Elvidge C D, Tuttle B T, Sutton P C, et al. Global distribution and density of constructed impervious surfaces. Sensor, 2007, 7: 1962-1979

17 Lu D S, Weng Q H. A survey of image classification methods and techniques for improving classification performance. Int $\mathrm{J}$ Remote Sens, 2007, 28: 823-870

18 Liu Z H, Wang Y L, Peng J. Remote sensing of impervious surface and its applications: A review (in Chinese). Prog Geogr, 2010, 29: 1143-1152

19 Ridd M K. Exploring a V-I-S (Vegetation-Impervious Surface-Soil) model for urban ecosystem analysis through remote sensing: Comparative anatomy for cities. Int J Remote Sens, 1995, 16: 2165-2185

20 Yang L M, Huang C, Homer C G, et al. An approach for mapping large-area impervious surfaces: Synergistic use of Landsat 7 ETM+ and high spatial resolution imagery. Can J Remote Sens, 2003, 2: 230-240

21 Xian G, Homer C. Updating the 2001 National Land Cover Database impervious surface products to 2006 using Landsat imagery change detection methods. Remote Sens Environ, 2010, 114: 1676-1686

22 Lu D S, Tian H Q, Zhou G, et al. Regional mapping of human settlements in southeastern china with multi-sensor remotely sensed data. Remote Sens Environ, 2008, 112: 3668-3679

23 Lu D S, Weng Q H. Extraction of urban impervious surfaces from an
IKONOS image. Int J Remote Sens, 2009, 30: 1297-1311

24 Slonecker E T, Jennings D, Garofalo D. Remote sensing of impervious surface: A review. Remote Sens Rev, 2001, 20: 227-255

25 Wang H, Wu B F, Li X S, et al. Extraction of impervious surface in Haihe River Basin using remote sensing (in Chinese). J Remote Sens, 2011, 15: 388-400

26 Foley J A, DeFries R, Asner G P, et al. Global consequences of land use. Science, 2005, 309: 570-574

27 Wang F, Ge Q S. Estimation of urbanization bias in observed surface temperature change in China from 1980 to 2009 using satellite landuse data. Chin Sci Bull, 2012, 57: 1708-1715

28 Wang L, Li C C, Ying Q, et al. China's urban expansion from 1990 to 2010 determined with satellite remote sensing. Chin Sci Bull, 2012, 57: 1388-1399

29 Liu J Y, Liu M L, Zhuang D F, et a1. Spatial pattern analysis of Chinese modem land use change. Sci China Ser D: Earth Sci, 2002, 32: 1031-1040

30 Liu J Y, Zhang Z X, Xu X L, et al. Spatial patterns and driving forces of land use change in China during the early 21st century. J Geogr Sci, 2010, 20: 483-494

31 Kuang W H. Simulating dynamic urban expansion at regional scale in Beijing-Tianjin-Tangshan Metropolitan Area. J Geogr Sci, 2011, 21: 317-330

32 Kuang W H. Digital Reconstruction, Analysis and Simulation SpatioTemporally of Urban Land Use Information (in Chinese). Beijing: Science Press, 2012. 43-45

33 Klein R D. Urbanization and stream quality impairment. Water Resour Bull, 1979, 15: 948-963

34 Griffin D M, Grizzard T J, Randall C W, et al. Analysis of non-point pollution export from small catchments. J Water Pollut Control Fed, 1980, 52: 780-790

35 Schueler T K. Controlling Urban Runoff: A Practical Manual for Planning and Designing Urban BMPs. Washington: MWCOG, 1987. $1-10$

36 Schueler T K. The importance of imperviousness. Wat Prot Techniques, 1994, 1: 100-101

37 Tian G J, Liu J Y, Xie Y C, et al. Analysis of spatiotemporal dynamic pattern and driving forces of urban land in China in 1990s using TM images and GIS. Cities, 2005, 22: 400-410

38 Liu J Y, Zhan J Y, Deng X Z. Spatio-temporal patterns and driving forces of urban land expansion in china during the economic reform era. AMBIO, 2005, 34: 444-449

39 Meng W, Su Y B, Zheng B H. Analysis of current situation of water pollution and its control strategy for Chinese river basins (in Chinese). J Chin Inst Water Resour Hydropower Res, 2004, 2: 242-246

40 Yin $\mathrm{C}$ Q. Urban diffuse pollution: A new challenge to the rapid urbanization in China (in Chinese). Acta Sci Circum Stant, 2006, 26: 1053-1056

41 Ye M, Yang G S, Zhang W S, et al. Study on Urban Non-point pollution characteristics and pollution loads prediction model (in Chinese). Environ Sci Technol, 29: 67-69

42 Tian H Q, Liu M L, Zhang C, et al. The dynamic land ecosystem model (DLEM) for simulating terrestrial processes and interactions in the context of multifactor global change. Acta Geogr Sci, 2010, 65: 1027-1047

43 Xiong Z, Fu C B, Zhang Q. On the ability of the regional climate model RIEMS to simulate the present climate over Asia. Adv Atmos Sci, 2006, 3: 784-791

Open Access This article is distributed under the terms of the Creative Commons Attribution License which permits any use, distribution, and reproduction in any medium, provided the original author(s) and source are credited. 